Cadernos de Clio, Curitiba, n. ${ }^{\circ}$ 4, 2013

\title{
ISÓCRATES E O IDEAL PAN-HELÊNICO: UM DISCURSO DE UNIÃO NO SÉCULO IV A.C.
}

Luciane Felisbino ${ }^{1}$

Resumo: Este artigo tem por objetivo pensar a questão da identidade grega durante o século IV a.C., através de um dos discursos escritos por Isócrates, o Panegírico. Partindo da questão da independência política das póleis, procuro entender quais então seriam os elementos agregadores destes grupos, tentando perceber a partir de Isócrates, as relações entre as cidades gregas, principalmente Atenas e Esparta, e também entre elas e os persas.

Palavras-chave: Grécia Clássica, identidade grega, hegemonia ateniense, pan-helenismo, inimigo persa, póleis gregas.

\section{Introdução}

Quando se fala sobre a Grécia Antiga uma das primeiras coisas que nos vem à mente é seu sistema de organização: as póleis, mais comumente chamadas de cidades-estado, que podem ser definidas como comunidades humanas compostas pelos cidadãos (politai), sendo cada polis um sistema de governo autônomo, com suas próprias leis. (MOSSÉ, 2004, p.240). Além disso, a bipolarização sempre comentada sobre duas das maiores cidades - Atenas e Esparta - ajuda-nos a perceber o grau de autonomia deste sistema, uma vez que cada uma destas possuía, já no século V a.C., uma forma própria de governo - sendo a primeira uma cidade democrática

${ }^{1}$ Graduanda do $6^{\circ}$ período de História - Licenciatura e Bacharelado da UFPR, orientada pelo Prof. Dr. Renan Frighetto. Lattes: http://buscatextual.cnpq.br/buscatextual/visualizacv.do?id=K4631940Y3. 
e a segunda oligárquica. A partir disso, podemos nos perguntar em que medida existiria uma identidade comum a estes grupos que se organizavam de formas independentes e em que elementos esta se pautaria.

Primeiramente, faz-se necessário definir o que entendemos por identidade. Partiremos da conceituação de Jean-Pierre Warnier que a define como "o conjunto dos repertórios de ação, de língua e de cultura que permitem a uma pessoa reconhecer a sua vinculação a certo grupo social e identificar-se com ele.” (WARNIER, 2003, p. 16-17). Além disso, o autor comenta que a identificação ${ }^{2}$ seria contextual e flutuante, e que no quadro da globalização da cultura, que ocorre em nossos dias, um mesmo indivíduo poderia assumir identificações múltiplas. (WARNIER, 2003, p. 17). Podemos pensar, todavia, que não apenas na atualidade, mas também na antiguidade, seria possível que uma mesma pessoa possuísse múltiplas identificações. Assim, compreendemos que no interior da Atenas do século IV a.C. poderia haver grupos antagonistas - oligarcas e democratas com suas vinculações próprias, que em uma perspectiva diferenciada não deixariam de ser atenienses, pertencendo a uma forma de identificação comum. Desta mesma maneira, pensamos que as póleis gregas poderiam estar unidas por uma identidade comum, mesmo que esta possa ser contextual e flutuante.

François Hartog em seu livro O Espelho de Heródoto: ensaio sobre a representação do outro trata a questão da alteridade, demonstrando como o historiador do século $\mathrm{V}$ a.C. construiu uma imagem do que seriam os gregos na contraposição com o outro (HARTOG, 1999), costumeira-

\footnotetext{
${ }^{2}$ Termo que o autor prefere à identidade.
} 
mente visto pelos gregos como bárbaros, dentre os quais se destacam os persas. No entanto, se o maior contato que tiveram com outros povos durante o século V a.C., em especial com os persas durante as Guerras Médicas, possibilitaria aos gregos compreenderem-se como um grupo coeso, possuidor de características culturais comuns, diferentes daqueles a quem denominavam bárbaros; o que se seguiu até o domínio dos macedônios, Filipe II e Alexandre, no século posterior, foram as desavenças políticas que ajudariam a desagregar e levar ao enfraquecimento das póleis gregas.

Surgiriam, então, no século IV a.C. pensadores como Isócrates, que tinham o intuito de restabelecer a concórdia entre os gregos, para que estes em seguida se voltassem contra os persas, que continuavam a intervir em seus assuntos. (MOSSÉ, 2004, p.220-221). Assim, o objetivo deste artigo é pensar a questão da unidade e identidade grega a partir de um discurso de Isócrates, o Panegírico, escrito em 380 a.C., seis anos após ser instaurada a Paz do Rei, através dessas conceituações; procurando os elementos que segundo Isócrates estabeleceriam relações entre os gregos, formando entre eles laços identitários, e pensando nesta contraposição, feita pelo autor, com o outro persa.

Mas para entendermos melhor as questões referentes ao período, precisamos recuar aos acontecimentos do século anterior, principalmente os que dizem respeito a polis de Atenas e suas relações com os persas e as demais póleis gregas, para compreender as motivações do retórico ateniense em suas colocações. 
Cadernos de Clio, Curitiba, n. ${ }^{\circ}$ 4, 2013

\section{As guerras do século $\mathrm{V}$ a.C.}

Podemos dizer que o século V a.C. foi marcado por guerras e desavenças - tanto externas quanto internas. No âmbito externo, destacam-se as chamadas Guerras Médicas, que eternizariam os persas como o opositor grego por excelência. Após a vitória grega na Primeira Guerra Médica (491-490 a.C.), os atenienses, muito devido a Temístocles, reforçaram sua frota naval e fortificaram e transformaram o Pireu em porto, pois acreditavam na possibilidade de uma nova guerra. É interessante notar que a própria democracia parece ter sido estimulada pela vitória grega, e o temor dos atenienses era que caso os persas ganhassem uma nova guerra, estes lhes impusessem o governo do ex-tirano Hípias - que estava em contato com a corte persa (JONES, 1997. p.10-13). As Guerras Médicas acabariam por trazer à cidade de Atenas certa evolução interna, tanto no que diz respeito ao desenvolvimento naval, quanto ao alargamento político ocasionado por ele, uma vez que os marinheiros eram recrutados entre os cidadãos mais pobres, que não tinham recursos para adquirir a panóplia hoplítica $^{3}$ (MOSSÉ, 2004, p.198). Além disso, logo após a vitória sobre os persas, a Liga de Delos seria formada, em 478 a.C. - as cidades gregas passariam a ter como hégemon a polis de Atenas, e partiriam sob seu comando em auxílio a cidades ainda dominadas pelos persas na Ásia e Egito.

Devido ao papel que assume, Atenas se fortalece ainda mais e passa a predominar sobre as demais cidades, o que levou vários estudiosos afirmarem que a Liga de Delos transformara-se em um Império (arkhé) Ate-

${ }^{3}$ Indumentária de guerra, composta por espada, elmo, etc. 
niense (JONES, 1997. p.240). Este poder ateniense viria a causar preocupações para outras póleis, em especial Esparta; e logo se iniciaria um período de guerras entre os próprios gregos, encabeçadas pelas cidades de Atenas - à frente da Liga de Delos - e Esparta - que formaria a Liga do Peloponeso. A Guerra entre os Gregos também seria caracterizada por um confronto ideológico entre democratas e oligarcas (MOSSÉ, 2004. p.124), os primeiros representados pelos atenienses e os subsequentes pelos espartanos - embora houvesse grupos de diferentes orientações dentro de cada uma destas póleis. Além disso, a ameaça persa não havia sido completamente superada, uma vez que os espartanos foram por vezes financiados por estes durante a guerra contra os atenienses e seus aliados - fato que será lembrado por Isócrates em seu discurso, para reforçar a ideia de que os espartanos não seriam tão bons hégemon como os atenienses (ISÓCRATES, p. 232-233). No entanto, até mesmo os atenienses, de orientação oligárquica, firmaram aliança com os persas para que estes deixassem de apoiar os espartanos, em troca os oficiais atenienses derrubaram a democracia em Atenas, embora tenham conseguido se manter no poder apenas por um curto período de tempo, sendo a democracia restabelecida.

Assim, a Atenas do século IV a.C. era herdeira de todos estes acontecimentos, suas últimas batalhas ocorreriam durante o início deste século, tendo sido a guerra interrompida devido à Paz do Rei, acordo que seria firmado em 386 com o intuito de por fim às desavenças tanto entre as póleis gregas, quanto entre elas e a Pérsia (JONES, 1997. p.44-45). Desta forma, apesar de Atenas ter conseguido restabelecer, de certa forma, sua hegemonia no Egeu (entre 378 e 356 a.C.) e o Pireu e continuar sendo seu centro de trocas, a cidade não teria mais o poder de outrora. Além disso, 
Cadernos de Clio, Curitiba, n. ${ }^{\circ}$ 4, 2013

as póleis, já enfraquecidas pelas guerras, continuavam desunidas e vulneráveis a ataques externos.

\section{A identidade grega no século IV a.C.}

É também no século IV a.C. que surge o pan-helenismo, que como já foi comentado, tem por objetivo propor uma aliança entre as póleis a fim de uni-las contra o perigo bárbaro - uma vez que o sentimento de pertencimento a uma mesma cultura teria sido reforçado com o contato e a contraposição aos persas, além da necessidade de se por um fim às guerras que enfraqueciam as póleis. Esse sentimento de pertencimento seria reforçado também por fatores como a língua ${ }^{4}$ - a koiné tendia a substituir dialetos locais - e festividades nos santuários pan-helênicos, onde discursos, como o Panegírico, seriam proclamados incitando a novas alianças gregas. (MOSSÉ, 2004, p.220-221).

O retórico ateniense Isócrates (436-338 a.C.) sendo contemporâneo à Guerra do Peloponeso e aos conflitos remanescentes com os persas, perceberia o desgaste que as guerras internas ocasionavam às cidades, que beneficiariam somente aos bárbaros. Assim, a oposição entre os gregos e persas parecem fortalecer-se na obra de Isócrates, uma vez que mesmo depois das Guerras Médicas terem findado, estes continuavam a estender seus braços nos assuntos gregos. Até mesmo a paz interna havia sido conseguida através de um acordo entre gregos e persas:

\footnotetext{
${ }^{4}$ Elemento que segundo Warnier estaria no centro dos fenômenos de identidade (WARNIER, 2003, p.16).
} 
"Se verá então que limitamos o império do Rei, impusemos a ele alguns tributos e o impedimos de utilizar o mar; mas agora é o Rei que governa os assuntos dos gregos, que ordena o que cada um deve fazer e só o falta impor governantes às cidades. Pois, fora isto, o que lhe falta fazer? Não foi senhor da guerra, dirigiu a paz e se fez árbitro dos assuntos presentes?" 5

Neste trecho, além da insatisfação com o fato do Grande Rei estar “governando os assuntos dos gregos”, Isócrates compara este momento presente, no qual os espartanos estabelecem-se como o hégemon, e um momento passado, no qual os atenienses encontravam-se nesta posição, e ao contrário dos primeiros, impunham limites aos persas, não deixando que os bárbaros os governassem. Assim, retomando os feitos passados da cidade, o retórico traz uma contraposição entre as duas póleis, para demonstrar que Atenas é quem deveria liderar os gregos em uma guerra contra o real inimigo, os persas, devido a todas suas antigas ações valorosas - citando desde a primazia que tiveram nas colonizações em outras regiões, que abriria caminho para que outras cidades fizessem o mesmo (ISÓCRATES, p. 208-209), até as vitórias gregas sobre os persas sob o comando ateniense (ISÓCRATES, p. 218).

Como expõe Laura Sancho Rocher esta discussão, sobre qual cidade seria a mais preparada para levar os gregos a uma campanha contra a Pérsia, tomaria ainda mais ares políticos devido à oposição que faz à oli-

\footnotetext{
${ }^{5}$ Tradução livre. "Se verá que entonces limitamos el imperio del Rey, le impusimos algunos tributos y le impedimos utilizar el mar; pero ahora es el Rey quien gobierna los asuntos de los griegos, ordena lo que debe hacer cada uno y sólo le falta imponer gobernadores en las ciudades. Pues, salvo esto, ¿qué le queda por hacer? ¿No fue señor de la guerra, dirigió la paz y se hizo árbitro de los asuntos presentes?” (ISÓCRATES, p. 232)
} 
Cadernos de Clio, Curitiba, n. ${ }^{\circ}$ 4, 2013

garquia espartana, pois esta, por ser um governo exercido por uma minoria, seria um exercício ilegal, apolítico e violento (ROCHER, 2002, p.236); ao passo que defenderia a democracia ateniense como uma das únicas capazes de representar “a autonomia política e os regimes constitucionais dos gregos, frente ao despotismo que representam os bárbaros.” 6 No entanto, Isócrates fala que não quer depor contra os espartanos, sendo seu intuito convencer o público do direito que os atenienses teriam de ser o hégemon.

Apesar desta contraposição que o retórico grego faz, entre as duas póleis, ele afirma:

"Sempre, nossos antepassados e dos lacedemônios, estiveram rivalizando entre si, mas naqueles tempos não os agradava competir, senão pelas coisas mais belas, na crença de que não eram inimigos, mas antagonistas; não serviam ao bárbaro para escravizar a Grécia, mas teriam o mesmo parecer sobre a salvação comum e disputavam qual dos dois seria seu autor.” 7

Se a situação contemporânea a Isócrates era de guerras e disputas entre as póleis, era exatamente contra isto que o autor se posicionava. Assim, ele remonta novamente ao passado para demonstrar que as duas

6 Tradução livre. "la autonomía política y los regímenes constitucionales de los griegos frente al despotismo que representan los bárbaros” (ROCHER, 2002, p.235).

${ }^{7}$ Tradução livre. "Siempre nuestros antepasados y los lacedemonios estuvieran rivalizando entre sí, pero en aquellos tiempos no les agradaba competir sino por las cosas más bellas, en la creencia de que no eran enemigos, sino antagonistas; no servían al bárbaro para esclavizar a Grecia, sino que tenían el mismo parecer sobre la salvación común y disputaban cuál de los dos sería su autor.” (ISÓCRATES, p. 221) 
cidades, Atenas e Esparta, não eram inimigas, mas apenas antagonistas na disputa entre qual delas levaria a liberdade aos gregos que se viam escravizados pelos persas. Na construção isocrática, a luta contra os persas nas Guerras Médicas também ganha ares de competição entre as duas póleis, que tentavam demonstrar o seu valor, sendo que para ele os espartanos tentavam igualar-se aos atenienses (ISÓCRATES, p. 223-224), sempre descritos como melhores que os primeiros - mesmo quando estes são descritos de forma positiva.

Entretanto, apesar de Isócrates primar pela colaboração entre as cidades contra o poderio persa, não podemos esquecer-nos das acusações que faz aos espartanos, de que estes estariam servindo aos interesses dos bárbaros (ROCHER, 2002, p. 234). Para o retórico ateniense parece perdoável que as póleis menores tenham se entregado ao poder do Grande Rei para que pudessem de alguma forma obter a salvação, mas reprova a atitude espartana pois seria "preferível para as cidades importantes desaparecer entre os homens ao ver-se na escravidão.” 8 Tudo isso deporia a favor dos atenienses na primazia pela função de hégemon no entender deste retórico.

Mas, se por um lado Isócrates defende que os atenienses deveriam liderar os gregos, por outro não deixa de reconhecer a importância dos espartanos, tanto no que diz respeito aos antigos feitos, quanto para uma futura empreitada militar. Sendo a guerra interna entendida, por ele, como o maior mal de seu período; o autor declara que o único bem que se poderia tirar dela seria a experiência obtida, e instiga os gregos a levarem a

\footnotetext{
${ }^{8}$ Tradução livre. "preferible para las ciudades importantes desaparecer de entre los hombres antes que verse em esclavitud” (ISÓCRATES, p. 224-225).
} 
guerra para fora de seu território, voltando-se contra os bárbaros - os persas (ISÓCRATES, p. 246). Assim, a guerra assumia um caráter ambíguo, pois se por um lado representava o mal, pela desestabilização e desagregação que causava no interior do mundo grego, por outro poderia ser um elemento de união e estabilização - caso voltassem suas forças contra o inimigo comum, os persas. Além disso, como demonstra Yvon Garlan, “a guerra socializada pode revestir-se positivamente de todos os valores de que a elite cívica se reclama” (GARLAN, 1994, p.51).

O desequilíbrio econômico e social causado devido aos ataques aos territórios gregos (GARLAN, 1994, p.55), aparece também como uma preocupação de Isócrates, uma vez que este comenta que

“o território que cada povo adquiriu não é auto-suficiente, mas carece de algumas coisas e tem excedente de outras, e como é muito difícil encontrar um lugar para vender algumas e importar outras, nossa cidade também ajudava nestas dificuldades; pois estabeleceu como um mercado no meio da Grécia, o Pireu." ${ }^{9}$

Mesmo destacando a importância dos atenienses e a centralidade do porto do Pireu, o retórico mostra que essa desunião interferiria nas questões de abastecimento das cidades, como um todo, pois devido ao território que possuem, precisariam umas das outras para conseguir os produtos que lhes faltavam. Sobre as questões econômicas, Claude Mossé nos lembra da importância da terra no mundo grego, no qual a própria questão de

\footnotetext{
${ }^{9}$ Tradução livre. "el territorio que ha adquirido cada pueblo no es autosuficiente, sino que carece de unas cosas y tiene excedentes de otras, y como es muy difícil encontrar un lugar donde vender unas e importar otras, nuestra ciudad también ayudaba en estas dificultades; pues estableció como un mercado en medio de Grecia, el Pireo” (ISÓCRATES, p. 210).
} 
cidadania ligava-se a ela, mas ressalta que no geral o solo grego não era muito fértil - com exceção da região do Peloponeso e das colônias do Ocidente - sendo necessárias importações de cereais do Egito, Cirenaica ou do Ponto Euxino (MOSSÉ, 1994, p.26). Assim, os conflitos entre os gregos além de devastarem seus campos, interferia neste sistema comercial dificultando a obtenção dos produtos dos quais careciam.

É interessante notar também o lugar no qual Isócrates coloca sua cidade, quando diz

“nossa cidade também ajudava nestas dificuldades” ${ }^{10}$, está reforçando certo caráter de benfeitora da polis ateniense. Diversas vezes durante a obra ele destaca situações que, para além de colocarem a cidade de Atenas em uma posição mais elevada frente as demais, demonstram a existência de laços de reciprocidade ligando-a às demais póleis a esta - que lhes trouxe não apenas os produtos dos quais necessitavam, mas também as libertou dos males da falta de governo e/ou da tirania, e serviu como modelo quer por sua primazia no estabelecimento das leis, quer na colonização de outras regiões (ISÓCRATES, p. 208-209).

Chega até mesmo a remeter a uma época mítica em que os atenienses teriam socorrido os filhos de Hércules, os quais dariam origem aos espartanos, o que evidenciaria que estes estariam em débito com os primeiros, enfatizando que "nenhuma tradição existe na qual os estrangeiros dominem os autóctones, nem os beneficiados a seus beneficentes, nem os

${ }^{10}$ Tradução livre. "nuestra ciudad también ayudaba en estas dificuldades” 
suplicantes àqueles que os acolheram.” ${ }^{11}$ Mais uma vez, Atenas encontrase na posição da bem-feitora, e como tal, deveria assumir o papel de hégemon, pois não faria sentido para ele que Esparta, como devedora, se encontrasse nesta posição.

Tomemos emprestado da antropologia o conceito de reciprocidade, como o apresenta Maurice Godelier, para tentar pensar estas relações entre as póleis gregas, pois no discurso de Isócrates, Atenas aparece sempre na posição de bem-feitora, daquela que ofereceu alguma dádiva, mas que ainda espera pela retribuição desta. Segundo Godelier, as relações sociais e hierárquicas seriam organizadas a partir dessas prerrogativas básicas da reciprocidade - dar, receber e retribuir (GODELIER, 2001). Assim, podese compreender a ênfase do autor nos feitos atenienses que beneficiaram a outras póleis, em especial Esparta; pois colocá-la como a distribuidora das dádivas no mundo grego, tanto a colocava em uma posição hierárquica superior às demais cidades, quanto demonstrava os laços que elas tinham entre si, caracterizando-as como um grupo.

Dentre todas as supostas dádivas atenienses que Isócrates comenta em sua obra, é importante apontar para a questão da educação, associada à filosofia e à oratória.

"Nossa cidade superou tanto aos demais homens em pensamento e oratória que seus discípulos chegaram a serem mestres de outros, e conseguiram que o nome de gregos não se aplique a raça, mas à in-

11 Tradução livre. ninguna tradición existe que de los foráneos dominen a los autóctonos, ni los beneficiados a sus bienhechores, ni los suplicantes a quienes les acogieron” (ISÓCRATES, p. 216). 
teligência, q que se chame de gregos mais aos participantes de nossa educação que os de nosso mesmo sangue.” 12

Neste trecho pode-se perceber a relevância atribuída pelo retórico à questão da educação, uma vez que ele coloca como elemento fundamental para a identificação deste grupo, não a questão da raça ou sangue, mas a formação cultural. Pretendendo apropriar-se da antiga linha educativa da paidéia, sua retórica estaria ligada aos valores morais da aristocracia e às questões políticas (CAMBIANO, 1994, p.101). Jaeger o liga a uma herança de pensamento ao qual pertencem Péricles e Tucídides, que atribuiriam aos atenienses uma tendência à alta cultura do espírito; além disso, segundo o autor, ao atribuir à sua cidade a fundação da cultura, dava a ela um caráter de coletividade que o contraporia às ideias de Platão. (JAEGER, 2001, p.1065-1066). Afirma que "Isócrates quer salientar aqui a cultura geral, em oposição a um determinado dogma ou método de conhecimento, tal como os platônicos o exigiam” (JAEGER, 2001, p. 1065), seria então a retórica que melhor plasmariam as exigências políticas e éticas da época, convertendo-as em um patrimônio universal (JAEGER, 2001, p.1067).

Assim, podemos pensar que esta cultura geral, que segundo Isócrates originara-se em Atenas e fora levada a outras partes, seria mais um elemento agregador dentro do mundo grego, que serviria também para diferenciá-los dos demais povos, vistos como bárbaros. Além disso, abri-

\footnotetext{
12 Tradução livre. "Nuestra ciudad aventajó tanto a los demás hombres en el pensamiento y oratoria que sus discípulos han llegado a ser maestros de otros, y ha conseguido que el nombre de griegos se aplique no a la raza, sino a la inteligencia, y que se llame griegos más a los partícipes de nuestra educación que a los de nuestra misma sangre" (ISÓCRATES, p. 212-213).
} 
Cadernos de Clio, Curitiba, n. ${ }^{\circ}$ 4, 2013

ria precedentes para colocar no seu interior grupos antes vistos como bárbaros - o que acontecerá com os macedônios, descritos como bárbaros no Panegírico, mas que são colocados como herdeiros da cultura grega em Filipe.

No Panegírico, Isócrates esforça-se para demonstrar as virtudes gregas em contraposição com os vícios e falhas de seus inimigos persas, colocando-os como inferiores e covardes, a quem não teriam motivos para temer (ISÓCRATES, p. 238-240). Mas a maior contraposição cultural seja talvez a questão da liberdade grega com a escravidão atribuída aos bárbaros, afirma:

"E aqueles deles que gozam de maior estima nunca viveram em igualdade nem em sociedade com outros nem com o estado, e passam toda a sua vida injuriando uns e escravos de outros, como homens que corrompem inteiramente suas naturezas, afeminam seus corpos por causa da riqueza e tem seus espíritos humilhados e pusilânimes pela monarquia.” 13

Nesta passagem o autor demonstra que até mesmo os melhores dentre os bárbaros nunca teriam vivido em "igualdade e sociedade” - prerrogativas gregas - e estariam corrompidos por seus vícios. Neste caso, a monarquia assume sua face negativa, representando tudo o que Isócrates se colocava contra - como expõe Rocher, a falta de justiça, a arbitrariedade e a tirania de um ou poucos (ROCHER, 2002, p.243). E por estes moti-

\footnotetext{
${ }^{13}$ Tradução livre "Y quienes de ellos gozan de la mayor estimación nunca vivieron en igualdad ni en sociedad con otros ni con el estado, y pasan toda su vida injuriando a unos y esclavos de otros, como hombres que corrompen enteramente sus naturalezas, afeminan sus cuerpos a causa da riqueza y tienen sus espíritus humillados y pusilánimes por la monarquía” (ISÓCRATES, p. 240).
} 
vos afirma que os bárbaros seriam mais educados para a escravidão que os escravos gregos (ISÓCRATES, p.240). O homem grego em contraposição seria livre, pois devido ao seu sistema político não se submetia as ordens de um rei, mas formariam no interior da cidade uma politéia, na qual os cidadãos possuíam também participação nas decisões da vida pública. (MOSSÉ, 2004, p.241)

Após toda essa reflexão, podemos compreender que Isócrates, tendo vivido durante um período de guerras internas e sofrido os males destas, procure meios de sanar este mal, propondo a união entre as póleis, e se o meio que encontra de agregá-las seria uma guerra comum contra um inimigo maior, ou como ele colocaria, o inimigo verdadeiro, isso se deve também a tradição que após as Guerras Médicas perpetuaria os persas como tal, e também ao fato destes ainda intervirem nos assuntos internos ao ambiente grego. Desta forma, necessidade de Isócrates de ressaltar os elementos comuns que ligavam as póleis pode ser entendido como fruto das guerras que ocorriam no período, dos efeitos negativos que estas traziam às cidades-estado. Desta forma, a constituição de uma identidade comum poderia contribuir para o término destes conflitos, mesmo que isso significasse a investida contra um inimigo comum - o outro persa.

Além disso, é importante pensar que durante todo o discurso elaborado no Panegírico, o autor, mesmo primando pela superioridade ateniense, procura sempre encontrar elementos que demonstrem a ligação existente entre as póleis, passando por fatores econômicos, políticos, culturais, etc., dando grande ênfase nas relações que se fizeram entre elas desde os tempos antigos. Assim, podemos concluir que mesmo as cidades 
gregas apresentando um quadro político independente, possuindo até mesmo sistemas de governo diferentes entre si, as relações entre as póleis as inseriam dentro de um conjunto maior, o qual compartilhava características culturais, podendo-se ressaltar a questão da importância da liberdade e igualdade política, e que era de alguma maneira interdependente.

\section{Bibliografia}

CAMBIANO, G. Tornar-se Homem. In: VERNANT, J.-P. O Homem Grego.Lisboa: Presença, 1994. p. 75-101.

GIORDANI, M.C. História da Grécia. Petrópolis: Vozes Ltda, 1972.

GARLAN, Y. O homem e a Guerra. In: VERNANT, J.-P. O Homem Grego.Lisboa: Presença, 1994. p.47-73.

GODELIER, M. O Enigma do Dom. Rio de Janeiro: Civilização Brasileira, 2001. Cap. 1.

HARTOG, F. O Espelho de Heródoto: ensaio sobre a representação do outro. Belo Horizonte:UFMG, 1999. p.229-271.

ISÓCRATES. Discursos I. Editoral Gredos. p.199-250.

JAEGER, W. Paideia: a formação do homem grego. São Paulo: Martins Fontes, 2001.p.1060-1110.

JONES, P. V. (org). O Mundo de Atenas: Uma Introdução à Cultura Clássica Ateniense. Martins Fontes: São Paulo, 1997.

MOSSÉ, C.; RAMALHETE, C., TELLES, A. Dicionário da Civilização Grega. Rio de Janeiro: Jorge Zahar, 2004.

MOSSÉ, C. O Homem e a Economia. In: VERNANT, J.-P. O Homem Grego. Lisboa: Presença, 1994. p.23-45.

ROCHER, Laura Sancho. Las fronteras de la política. La vida política amenazada según Isócrates y Demóstenes. In: Gerión, Madrid. v.20, n.1, 2002. p. 231-253.

WANIER, J.-P. A mundialização da cultura. Bauru: EDUSC, 2003. 